\title{
O sentido da fenomenologia na Psicopatologia Geral de Karl
}

\section{Jaspers}

Guilherme Messas ${ }^{1}$

Resumo: Com o centenário da publicação da primeira edição da Psicopatologia Geral de Jaspers, é pertinente uma avaliação do valor de sua obra. Este artigo procura examinar o sentido de uma parte específica da Psicopatologia Geral, a fenomenologia. Para que se possa entender de modo legítimo o sentido de uma ciência parcial na Psicopatologia Geral é necessário inicialmente a apreensão da lógica global da obra, qual seja, a relação dialética entre partes e todo. O trabalho parte da investigação dessa relação, apresentando como a solução filosófica encontrada por Jaspers para equacioná-la - o círculo hermenêutico elege os métodos como o princípio ordenador da psicopatologia geral. Assim sendo, a fenomenologia como ciência empírica na Psicopatologia Geral é apenas um método de investigação da realidade, devendo ser separada das reflexões filosóficas acerca da existência.

Palavras-chave: Jaspers; Psicopatologia Geral; fenomenologia; filosofia da psiquiatria; relação partes-todo; psicopatologia fenomenológica.

\begin{abstract}
One hundred years after the publication of the first edition of Karl Jaspers' General Psychopathology, it is relevant an evaluation of its value. This article examines one section of this work, the phenomenology. In order to

\footnotetext{
${ }^{1}$ Médico psiquiatra. Mestre em Medicina e Doutor em Psiquiatria pela USP. Membro fundador da Sociedade Brasileira de Psicopatologia Fenômeno-Estrutural. Coordenador da Especialização em Psicopatologia Fenomenológica da Faculdade de Ciências Médicas da Santa Casa de São Paulo. Email:messas@fenomenoestrutural.com.br.
} 


\section{O sentido da fenomenologia na Psicopatologia Geral de Karl Jaspers}

understand the meaning of a partial science in General Psychopathology, it is necessary the global aprehension of the work, i.e. its emphasis on the dialetical relationship between parts and totality. This article demonstrates that the notion of hermeneutic circle is the main principle of the General Psychopathology. As a consequence, phenomenology as an empirical science is, for Jaspers, only a particular investigation method, separated from philosophical reflections on existence.

Keywords: Jaspers; phenomenology; philosophy of psychiatry; relations partstotality; phenomenological psychopathology.

O mero fato da pertinência de uma reflexão comemorativa do centenário de publicação de uma obra relacionada de algum modo a uma ciência empírica já atesta sua singularidade. Raramente um trabalho intelectual individual levando em consideração - ainda que em parte apenas - conhecimentos provenientes de aportes tecnológicos renovados diariamente consegue sobreviver mais do que uma geração. Os dados novos desbotam o valor dos anteriores, as técnicas mais atuais conduzem ao ostracismo as prévias e a massa infinita de novas contribuições no conjunto da ciência fazem com que apenas trabalhos coletivos sempre atualizados possam permanecer vivos como polos de difusão do conhecimento. A Psicopatologia Geral (PG) de Karl Jaspers, cuja primeira edição se deu em 1913, parece escapar a esse destino comum. Cem anos após sua vinda à luz, ainda resiste na comunidade de especialistas a ideia de que seja necessário sobre ela refletir, não como efeméride de um ponto do passado apenas inaugural, mas como edifício científico a ser visitado obrigatoriamente na formação de novos psiquiatras. Constituiria essa atitude um erro motivado pela nostalgia de alguns que, diante das enormes, complexas 


\section{Guilherme Messas}

e desordenadas novidades diuturnas da psiquiatrias, pregam o retorno a um eldorado perdido, no qual idealmente a psiquiatria teria tido seu apogeu intelecutual? Ou, pelo contrário, a psiquiatria contemporânea, recebendo influxos incessantes da tecnologia sobretudo neurocientífica, teria ainda algo a receber de constituinte da PG, justificando que seu estudo cuidadoso se mantivesse nas formações dos psiquiatras e que funcionasse como ponto de apoio das discussões técnicas e metodológicas? Da resposta a essas questões depende o local em que colocamos a PG no seu segundo jubileu, se de homenageada póstuma ou farol sempre reverenciado. E não são poucas as diferenças de atitude entre lermos uma obra como produto de um passado respeitável, mas obsoleto - atitude de historiador - e a estudarmos como psiquiatras em contínuo aperfeiçoamento de nossa atividade - atitude técnica. Na primeira, há uma distância insuperável entre observador e obra, um diálogo apenas exterior entre ambos; por outro lado, na segunda, o observador deve se deixar plasmar pela obra, por ela ser configurado por meio de um diálogo interior.

É evidente que para mensurarmos a eventual vitalidade de uma obra é necessária uma investigação acerca do que a contemporaneidade atesta como valor, pois normalmente é a partir dessa hierarquia de valores atuais que se recortam as obras do passado: ou seja, as obras do passado são mutiladas em sua integridade para que alguns de seus aspectos parciais possam servir aos interesses dos olhares de outra época. Não há absolutamente nada de incorreto nesse procedimento, já que é exatamente assim que transcorre a história das práticas científicas. Apenas devemos nomear essa atitude como "exterior", já que examina o valor da obra não pelas suas características intrínsecas, mas por aquilo que outro quadro de valores recolhe dela. Por outro lado, existe a modalidade de análise de uma obra que poderíamos nomear "interior", na qual se procura estudá-la a partir das estruturas de pensamento e interesses 


\section{O sentido da fenomenologia na Psicopatologia Geral de Karl Jaspers}

buscados efetivamente pelo autor. Embora as atitudes "exterior" e "interior" não sejam excludentes - pelo contrário, elas deveriam ser intimamente ligadas é hábito, sobretudo nas ciências vinculadas a práticas, que apenas a "exterior" seja efetuada, já que a "interior" exige um rigor lógico e um aprofundamento tais que desviariam o cientista de seus afazeres cotidianos ligados ao campo científico empírico. Em nome da procura de conclusões extraídas de uma abordagem rigorosa, na realidade o pesquisador deveria examinar incialmente o ponto de vista "interior" para apenas a seguir cotejá-lo com o "exterior", ou seja, para nosso caso de interesse, conhecer a estrutura interna da PG para então aquilatar seu valor para a contemporaneidade.

Mas essa é uma tarefa gigantesca que transcenderia em muito os limites de um artigo. Minha ambição neste trabalho é bastante mais estreita: examinar “interiormente" a PG de Jaspers a partir de uma indagação que se dá do "exterior". Esse "exterior" a que me refiro é a corrente fenomenológica (voltaremos ainda à sua definição) em psicopatologia, uma tradição que mantém certa relação ambígua, de afastamentos e aproximações com a PG , mas que a tem como, no mínimo, eixo de discussões. Este artigo resume-se à retomada da questão acima - de onde situar o valor da PG - a partir da ênfase em uma das suas partes, a fenomenologia. Nesse sentido, é uma questão "exterior" - pois o isolamento da fenomenologia na PG como unidade de investigação é artificialmente dada pelos interesses fenomenológicos contemporâneos -, fundamentada em uma investigação "interior" da situação e papel da fenomenologia na PG. Uma vez tendo circunscrito "interiormente" o tema é que nos permitiremos, ao final, apontar algumas sugestões acerca da vitalidade da PG para a psicopatologia fenomenológica contemporânea.

Embora enfatizaremos um recorte da PG - sua fenomenologia - a aproximação pela atitude "interior" exige que se busque identificar inicialmente 


\section{Guilherme Messas}

o princípios regulamentadores da obra, aqueles que dão sentido de conjunto para as partes. Como demonstraremos a seguir, passar ao largo disso constituiria uma mutilação intelectual que anularia quaisquer resultados acerca da PG, dadas as suas características peculiares. Utilizaremos para essa trabalho a sétima e última edição da Psicopatologia Geral, publicada em 1959. O tema das edições merece alguma consideração. A edição de que ora comemoramos o centenário é a primeira, de 1913. De modo algum esta primeira edição se manteve inalterada. Seguindo os prefácios de cada edição, se vê que a quarta (1942, publicada somente em 1946) conheceu uma reforma completa, na qual Kurt Schneider representou papel relevante, assim como outros, para a atualização da massa de escritos empíricos. Entretanto, o propósito da obra manteve-se inalterado, com importante acréscimo das ideias próprias do autor. Do mesmo modo, na sétima edição pode-se ler que “...os princípios de ordenação metodológica permanecem...amplamente inalterados" (p.V), permitindo que o autor concluísse que, embora alguns conteúdos empíricos, cerebrais e somáticos exigissem atualizações, a obra não estivesse superada (ibidem). Dessa maneira, ao avaliarmos a PG no seu centenário, estamos de fato a investigar um trabalho de maturação gradual que, ainda que transformado, segue os mesmos princípios de sua origem. Mais um argumento para que um mergulho na PG que faça jus a seus propósitos se faça pelos seus princípios de ordenamento.

\section{A tensão entre o todo e as partes na Psicopatologia Geral}

Filósofo de rara estirpe, Karl Jaspers ilumina com clareza lógica todas as passagens responsáveis pela determinação dos objetivos primordiais de sua obra-prima. Eles são dados já na sua introdução - longa, porém, imprescindível 


\section{O sentido da fenomenologia na Psicopatologia Geral de Karl Jaspers}

para o entendimento da PG: "A psicopatologia geral não tem a tarefa de recapitular todos os resultados, mas de configurar um todo" (Jaspers, 1959b, p. 33). Uma psicopatologia, para ser "geral", deve procurar abarcar a noção de totalidade, superando, pois as psicopatologias parciais, que podem se limitar a certas afecções e suas condições de manifestação. $\mathrm{O}$ protagonismo da procura por uma totalidade como objetivo da PG não pode ser subestimado nem em suas dificuldades de aplicação nem na amplitude de seu valor. Na realidade, esses dois polos alimentam-se reciprocamente. O ideia do todo só tem valor supremo porque não se aplica de modo leviano, simples e evidente, mas resulta de um esforço continuado e autocrítico da razão do investigador, buscando identificar uma ordem superior a arranjar os elementos parciais. Ordem superior que, embora não estando diretamente exposta nos achados, permanece como superordenação ativa, enfeixando-os sem se mostrar e exigindo um ato de pensamento que a revele. Essa noção de totalidade só pode ser entendida completamente tendo em vista a filosofia existencialista de Jaspers, que surge de modo disperso em inúmeros momentos da PG. É antes um princípio que, embora fugidio, não pode ser abandonado se se desejar atacar a complexidade da vida humana e de seu adoecer mental. Analogamente, a sua difícil aplicação vem do fato de que, recusada a leviandade, há que se tatear sempre o campo empírico em busca das regiões nas quais se pode implantar com fecundidade uma noção de todo que não apenas pode ser abandonada transversalmente logo adiante por uma de melhor capacidade sintética, como necessariamente é subsumida verticalmente por uma outra totalidade, a ela superior. Isso se dá pelo fato contraditório em si de que, embora sua investigação deva culminar em uma noção de totalidade, "O homem é incompleto em sua essência e inacessível em si mesmo ao conhecimento." ! (Jaspers, 1959b, p. 625). Ora, como é possível erigir-se uma psicopatologia geral, que visa sempre ao todo, se esse todo final a essência - está já de saída neutralizado? Como conhecer algo de confiável da 


\section{Guilherme Messas}

totalidade do mundo existencial humano sem se despedir da concepção de que esse mesmo mundo é em si incognoscível?

Jaspers recusa veementemente a simplificação psicopatológica que consistiria em aplicar o todo à realidade empírica de maneira genérica, "abstrata". Tampouco em momento algum pretende desistir dessa noção de totalidade, cedendo a uma apresentação plural de resultados das ciências psicopatológicas particulares, composta apenas por partes exteriores, arranjadas lateralmente entre si, à moda dos tratados típicos de psiquiatria. Nestes, em geral, após uma introdução, as patologias, suas definições, condições de produção e tratamento sucedem-se entre si, inexistindo uma relação orgânica entre as partes. Os temas na PG, por sua vez, "estão em relação uns com os outros, não em contiguidade mecânica" (Jaspers, 1959b, p. 41). A singularidade de Jaspers como filósofo da psiquiatria radica justamente na compreensão da impossibilidade de se separar uma noção proveniente da filosofia, a totalidade - conceito capital para o existencialismo do autor-, do conjunto de conhecimentos científicos empíricos e seus conceitos e estilo de produção intelectual. A perseguição da totalidade por Jaspers na PG - totalidade que é, no limite, intraduzível em termos de ciência - não deverá cegá-lo diante das particularidades nas quais é possível se estabecer um conhecimento científico de caráter válido e universal. Importante ressaltar que Jaspers sempre restringiu a definição de ciência psicopatológica àquilo que deve ter caráter de validade universal: tudo o que, relativo à vida humana, escapar a isso, é terreno da filosofia, para a qual reserva sublime papel, mas de natureza diversa à científica.

Não é irrelevante indicar a força com que Jaspers preocupa-se com a aplicação universalizante e irresponsável da noção de totalidade na psicopatologia, pois ela não deixa de expressar a importância que dá ao 


\section{O sentido da fenomenologia na Psicopatologia Geral de Karl Jaspers}

conceito e de mostrar como ele atua na organização da PG. O centro da sua crítica ao uso irresponsável da noção de totalidade encontra-se nas suas reflexões acerca das "teorias" em psicopatologia. Por teoria define toda construção intelectual que organiza as relações de conexão entre fenômenos lançando mão de conceitos e modelos que jamais podem passar pela consciência efetivamente vivenciada pelo paciente. Assim, por exemplo, todas as hipóteses causais tanto cerebrais (neurocientíficas, diríamos atualmente) quanto psicanalíticas (psicodinâmicas, na linguagem contemporânea), embora possam e devam ser testadas em campo científico, são teorias para Jaspers. A noção de teoria em si não é desprezada pelo autor, que as entende como necessária para qualquer empreendimento científico; contudo, na sua má aplicação em relação à noção de totalidade reside um perigo nada negligenciável:

“Impera (em todo pensamento teórico) um entusiasmo por ter captado o verdadeiro e o todo da realidade psíquica... As teorias costumam aparecer com a pretensão de dominar o todo. Os teóricos têm a consciência instintiva de ter reconhecido de algum modo a causa mesma em profundidade, de maneira definitiva, de ter captado o todo de um golpe. (Japers, 1959b, p. 459) ... Na origem histórica da formação de teorias há, na verdade, princípios no mais das vezes fecundos. Intuições antecipadoras de um todo abrem novos espaços para as investigações, criam como que novos órgãos de apreensão. Mas logo é o próprio instinto teórico que paralisa essa fecundidade, ao pretender haver captado... o ser propriamente real e fundamental (Japers, 1959b, p. 460)"

Em essência, a teoria não erra na sua procura legítima por uma totalidade, mas no autoengano de acreditar tê-la encontrado, pois esse engano é cego para o fato da incompletude do humano. Nesse sentido, portanto, o objetivo mais filosófico da PG é organizar um complexo edifício científico sem 


\section{Guilherme Messas}

desacoplar-se das características do objeto a ser estudado: é apresentar como se faz ciência empírica, necessariamente parcial, sem se esquecer que, sendo total, o objeto estará sempre mais além da cognoscibilidade possível, dissolvido na “...confusa plenitude da rica vida real” (ibidem).

Se as totalidades são o objetivo principal da PG e não podem ser interpretadas de modo absoluto, Jaspers terá de enfrentar o problema de como formulá-las. Já vimos como há o conceito antropológico de uma totalidade inabarcável, a existência em sua singularidade. Esta totalidade-limite escapa do escopo da ciência e deve ser abordada pela mentalidade filosófica. Não faria sentido, portanto, uma psicopatologia geral que se dedicasse estritamente aos problemas das existêncas singulares. A PG deve se dedicar ao estudo e organização das ciências particulares tendo em vista uma ideia estruturante de totalidade. Para isso, há que se estabelecer, no campo empírico, uma relação dialética entre as ciências particulares e a totalidade. Essa relação dialética faz com que o sentido de totalidade na PG seja duplo. Por um lado, existe a totalidade-limite, relativa à existência, objeto da filosofia; por outro, espécies de "totalidades parciais" que emergem da relação dialética respectiva com cada uma das ciências parciais e que se estruturam também entre si (entre as totalidades parciais) em planos. Essa complexidade crescente - em direção progressiva - de amarras dialéticas entre ciências particulares parciais e suas totalidades também parciais, visando a uma totalidade-limite incognoscível, é fundamental para a estrutura da PG. Sem seu entendimento, talvez não se possa abordar a PG senão levianamente, traindo o espírito do autor.

Mas devemos entender esse caminho progressivo não no sentido hierárquico, ou seja, de que as últimas totalidades têm valor ontológico maior do que as anteriores. Na realidade, trata-se apenas de uma progressão heurística do mais captável em termos unitários - menos complexo, portanto - 


\section{O sentido da fenomenologia na Psicopatologia Geral de Karl Jaspers}

para o mais complexo. A modalidade dialética de progressão entre as parcialidades psicopatológicas que orienta Jaspers na PG não está explicitada. Contudo, preserva o espírito de sua própria concepção de "dialética como síntese", exposta na seção sobre relações de compreensividade. Lê-se ali que nesta forma de dialética “...as oposições combatem umas com as outras: o polarmente contraposto se encontra presente na mesma alma, arrojando-se um contra o outro", constituindo “...uma tensão construtiva” (Jaspers, 1959b, p. 284). Ou seja, transportada essa concepção para a estrutura da PG, vê-se que as ciências parciais articuladas em termos de totalidades sintéticas jamais deixam de manter seu perfil integral, ainda que enfraquecido pelas absorção pelas sínteses, o que trará consequências importantes para a determinação do papel da fenomenologia, como veremos. Para nosso propósito de esclarecer a posição de um segmento da PG, a fenomenologia, a observação de sua arquitetônica global é inevitável. Façamos essa inspeção da maneira mais sucinta e direta possível, enfatizando seu caráter progressivo.

Partindo da introdução, vemos que o tema escolhido para abertura da obra não é casual. Toda psicopatologia inicia-se da irredutibilidade de alguma experiência patologicamente vivenciada por um indivíduo. Portanto, o primeiro passo para uma psicopatologia é o estabelecimento do conjunto de fatos que a justifica. A ciência que examina, descreve e discrimina as vivências patológicas subjetivas é a fenomenologia. Essa ciência inaugural não deixa de ser - posto que é ciência - um conhecimento de partes. Serão as partes do psiquismo que, dissecadas de sua inserção global na vida consciente, deverão ser objeto do cientista da fenomenologia. No entanto, para Jaspers há uma insuficiência dessa ciência parcial, dada pela sua necessária subjetividade. No mesmo plano heurístico parcial da fenomenologia repousa a psicologia dos rendimentos, na qual as experiências individuais podem ser avaliadas na sua face "objetiva", reduzindo assim ao mínimo a incerteza de seus resultados. Ambas devem 


\section{Guilherme Messas}

caminhar juntas na investigação do psiquismo, mas devem ser dialeticamente sintetizadas e superadas nas suas respectivas totalidades. A primeira totalidade da PG: o "estado de consciência", sintetiza a fenomenologia. Assim, a investigação do todo momentâneo da consciência é o penhor dos achados parciais encontrados na fenomenologia. Por exemplo, uma determinada vivência descrita na fenomenologia apenas será nomeada patológica se o todo de consciência em que nascer estiver sob estado de vigília ou de rebaixamento. Da mesma maneira, os rendimentos objetivos da consciência dependem do conjunto das funções psíquicas para seu esclarecimento psicopatológico.

Esse primeiro plano de investigação psicopatológica - mais próximo da realidade experiencial do paciente e do investigador - não pode satisfazer o espírito de ciência, já que faz parte dos interesses desta o conhecimento dos modos de produção dos achados acima estudados. Trata-se, pois, de se estabelecer mais um plano de ciências psicopatológicas, as que tratam de relações de conexão da vida psíquica. Jaspers estabelece dois tipos de relações de conexão: compreensíveis e causais. As relações compreensíveis elucidam a produção do psíquico a partir do psíquico, constituindo uma espécie de relação genética "interna" à vida psíquica que pode ser compreendida psicologicamente pelo investigador. Por outro lado, há relações "externas", causais, que escapam da empatia do observador e exigem a introdução de um elemento não compreensível para o preenchimento dessa lacuna genética. As relações compreensíveis, por sua vez, são sintetizadas e recebem seu sentido a partir de uma totalidade particular, a caracterologia. O estudo do caráter é que orienta o sentido das compreensões particulares de cada fenômeno ou rendimento. As relações causais - ou explicativas - são totalizadas pelo elemento externo "teoria", acima mencionado. A teoria dá o valor de uma relação de causa e efeito que escapa à consciência vivenciada ou observada. Todos os elementos abaixo reunidos, por sua vez, recebem o timbre de mais um 


\section{O sentido da fenomenologia na Psicopatologia Geral de Karl Jaspers}

plano de totalização que, sintetizando-os de um só golpe, culmina nos quadros nosológicos e na eidologia (sexo, constituição e raça). Estas últimas ciências ainda necessitam ser totalizadas pelas suas relações com a temporalidade, desaguando na biografia, o último nível das totalidades sintéticas empíricas. Assim, se examinarmos o procedimento da PG de cima para baixo, teremos que toda investigação psicopatológica é uma biografia que arranja a nosologia, a eidologia, as relações de conexão dos caráteres e as explicações teóricas e compreensões psicológicas dos fenômenos e dos rendimentos objetivos. Tudo de uma só vez. Essas partes e totalidades parciais são a tal ponto articuladas que a visão global da PG mostra muitas vezes conteúdos repetitivos, já que fazem remissões reflexivas contínuas entre si. Mas, ainda por sobre todos esses, reina o capítulo final, essencialmente filosófico, que examina "o todo do ser humano". E para o qual a noção de todo é incerta, deslizante, ou seja, não há um todo que totalize a integralidade da existência humana, embora ele deva ser buscado.

Ja temos, portanto, apresentada em linhas gerais as condições de inserção das ciências particulares - das quais a fenomenologia faz parte - na PG, o que indica a dificuldade de examiná-las em separado e sobretudo afirmar seu valor individual. As amarras da totalidade na PG são tão fortes que, de certo modo, uma reflexão sobre uma parte, como faremos aqui, acaba sendo uma purificação fictícia. O nome dado por Jaspers a esse procedimento intricado entre todos e partes é "círculo hermenêutico", que o autor importa de Dilthy, um de seus mestres. 


\section{Guilherme Messas}

\section{O valor da ordenação metodológica}

Mas ainda não podemos considerar que vimos o mínimo suficiente para entender o papel parcial da fenomenologia na PG. Ainda é necessário apresentar de que modo é possível se construir um edifício intelectual tão portentoso e ambicioso. Temos o problema de que a ciência não é capaz de atingir a totalidade da existência humana, aberta por natureza e objeto exclusivo da filosofia. Se fosse possível o estabelecimento de uma antropologia geral que norteasse todos os achados científicos, a tarefa de ordenação psicopatológica pela ideia de totalidade estaria bastante facilitada. É o que Jaspers censura, por exemplo, na psicanálise. Freud, tendo estabelecido um entendimento geral sobre a existência humana, deriva todos seus achados dessa compreensão, realizando uma obra cujos resultados seguem essa noção-chave. Por exemplo, a partir da teoria da pulsão faz derivar toda a psicopatologia, desde a histeria até a psicose, passando pela obsessão e pela melancolia. Todos os resultados científicos são justificados pelo mesmo método que, por sua vez, se defende pela mesma teoria total.

Posto que Jaspers recusa essa totalidade fechada, encontra-se diante da situação de estar privado de um sustentação intelectual geral para todos os resultados das ciências. Não havendo uma antropologia geral, tampouco pode haver um método geral avalizando e dando sentido a todos os resultados e, mais importante ainda, permitindo que os resultados e a antropologia geral se confirmassem mutuamente. Assim, Jaspers deve restringir-se a guiar a sua apresentação não pelos resultados das ciências, mas pelos métodos parciais e bastante diversos que sustentam cada juízo científico. Como vimos acima, como cada parcialidade mantém de certo modo sua independência ontológica mesmo quando sintetizado por uma totalidade, apenas é possível uma psicopatologia 


\section{O sentido da fenomenologia na Psicopatologia Geral de Karl Jaspers}

geral que demonstre como tais métodos produzem tais resultados. Para métodos parciais, resultados parciais e incapazes de construir ou se referir a uma antropologia geral. Tomemos um exemplo da própria introdução da PG para esclarecer melhor essa característica: "A ideia delirante deve ser considerada fenomenologicamente, do ponto de vista psicológico funcional, em relações de compreensão. ... aparecem portanto os mesmos fatos em diversos capítulos, fazendo com que aquilo que neles é 'o mesmo' se torne cada vez mais exterior por meio do conhecimento crescente" (Japers, 1959b, p. 40). Tudo isso orientado por uma noção de totalidade incapaz de abarcar o todo científico. É inegável que essa estratégia pode gerar uma atmosfera de confusão e imprecisão que o autor deve contornar.

Jaspers é ciente das críticas que pode receber a esse tipo de procedimento, passível de ser taxado de niilista em um ambiente científico otimista com suas próprias capacidades de encontrar o todo do homem e descrente da potência da filosofia. Diante da possível objeção de que

“Esta psicopatologia não dá um quadro objetivo fechado do todo; antes, o decompõe inteiro ou o deixa firmemente contíguo... não surge nenhum quadro do ser humano doente" (Japers, 1959b, p. 624).

Jaspers contrapõe que “...esta forma de estrutura básica é a consequência do fato de que não admitimos nenhum ponto de vista como o único válido, nenhum grupo de fatos como a realidade propriamente dita. Contra a tendência de uma dogmática do ser que se expressa em uma contrução do todo, levamos a cabo uma sistemática metodológica" (ibidem).

A decisão filosófica de manter a relação entre partes e todo em uma tensão dialética máxima e insoluvel é, em Jaspers, radical. A consequência desse radicalismo do círculo hermenêutico é que os métodos de obtenção da realidade psicopatológica, sempre parciais por natureza, valem mais como princípio de 


\section{Guilherme Messas}

ordenação do que os resultados dessa ciência. Se os resultados, separados de seus métodos, podem iludir-nos com a pretensão de abarcamento geral do homem, os métodos, como caminhos necessariamente parciais e de restrito poder conclusivo, serão o objeto por excelência do pensador da PG. Essa eleição dos métodos como objetos a serem organizados, aliada à chamada de nossa atenção para as relações espúrias provenientes da universalização de achados científicos desossados de suas raizes metodológicas é a principal e imorredoura contribuição intelectual de Jaspers à psicopatologia e, sem dúvida, à psiquiatria.

\section{A Fenomenologia como parcialidade}

Já temos então que (i) as ciências particulares devem ser inseridas em uma totalidade que as sintetize e que (ii) mais importante de que seus resultados é seu "estilo" de produção de resultados. Vejamos as consequências dessas duas posições.

Em primeiro lugar, o fato das ciências particulares serem dialeticamente independentes, mas subordinadas a um termo sintético fazem delas, tomadas individualmente, de valor relativo para o edifício global de uma psicopatologia geral. Jaspers enfatiza especialmente na fenomenologia esse caráter, rejeitando a identificação de sua obra a uma escola fenomenológica: “Há um mal-entendido quando se designa meu livro como 'obra principal da corrente fenomenológica'. A atitude fenomenológica é um ponto de vista e é exposta com especial detalhamento em um capítulo deste livro, por ser então novidade. Mas a ideia deste livro é justamente que é apenas um ponto de vista e, como o livro ensina, inclusive somente um ponto de vista subordinado" (Japers, 1959b, p. 42). Assim, devemos ter em mente que não apenas Jaspers relativiza o valor da sua 


\section{O sentido da fenomenologia na Psicopatologia Geral de Karl Jaspers}

fenomenologia como expressa sua distinção com aquilo que chama, com razão, de corrente fenomenológica. Não é gratuito e incorreto, portanto, que um dos mais importantes historiadores da psicopatologia fenomenológica, Arthur Tatossian, não veja nenhuma relação de ascendência entre essa modalidade de psiquiatria e psicopatologia e o método preconizado por Jaspers (Tatossian, 2006). Apenas nominalmente pode haver alguma identificação entre elas e é importante que o leitor tenha isso sempre em mente para procurar não confundi-las.

Examinemos agora brevemente como é entendido o objeto da fenomenologia na PG e as relações entre o método e seus resultados. Como na PG há curiosa e paradoxalmente apenas uma sumária apresentação do método fenomenológico, já que o autor se dedica sobretudo à demonstração dos seus resultados, usaremos eventualmente como apoio, nesta e na próxima seção, seu artigo de 1912 sobre "A abordagem fenomenológica em psiquiatria" (Jaspers, 1968). Embora não se faça menções explícitas a esse trabalho na PG, há uma evidente continuidade de sentido entre um e outro. A fenomenologia é essencialmente uma ciência das vivências patológicas dos pacientes. Portanto, sendo uma ciência da subjetividade, necessita fundamentalmente das autodescrições dos pacientes. Estas, entretanto, não podem ser tomadas inocentemente ao pé da letra. Há que se apurar o material recolhido das vivências autodescritas, purificá-las de elementos de confusão por parte do paciente e, conjuntamente, procurar representá-las a partir de um ato, por parte do psicopatologista, de empatia, por meio do qual é capaz de colocar-se "na mente do outro indivíduo" (Jaspers, op. cit, p. 1313) (Hineinversetzen). A fenomenologia visa, assim, a um quadro representacional de uma figuração de certa experiência do paciente, mas apenas em estado estático (op. cit. p. 1322). As modalidades de estudo das modificações no tempo estão excluídas do escopo da fenomenologia. 


\section{Guilherme Messas}

Porém, esses achados devem seguir rigorosamente a noção de parcialidade da ciência empírica, cuja aplicação particular aqui traduz-se pela necessidade de isolamento, discriminação e classificação dos fenômenos que tenham aspecto geral. Deve-se procurar determinar, por exemplo, dentro da consciência do objeto, o que é uma percepção e discriminá-la do que venha a ser representação para que se possa estabelecer a seguir a diferença entre uma alucinação e uma pseudo-alucinação. E não serão todos os fenômenos, mas apenas aquele “...cuja característica geral... pode ser encontrada igualmente em outro caso e portanto pode ser chamado de mesma característica..." (op. cit. p. 1320). Embora o apreço pelas complexidades do real faça com que Jaspers afirme que o isolamento e discriminação “...fazem os fenômenos mais puros e precisos do que são na realidade" (Jaspers, 1959b, p. 50), define sua fenomenologia como "...definitivamente orientada para o perceptível e concreto, não o abstrato" (op. cit. p. 1320). A partir desses preceitos metodológicos, pode-se encadear a tarefa inalienável de classificação dos fenômenos. Jaspers propõe três grupos: (i) fenômenos comuns a todos, (ii) fenômenos entendidos como exagero, diminuição ou combinações de fenômenos que todos experimentam e (iii) fenômenos completamente inacessíveis para o ato empático do psicopatologista.

Este é o quadro global da ciência fenomenológica para Jaspers, um saber com certa dose de abstração, já que estabiliza fenômenos singulares, retirandoos de seu fluxo temporal, mas seguramente instalado dentro do círculo das ciências empíricas, passíveis de universalização, comunicação e falsificação. Esse entendimento fenomenológico de Jaspers - se pudermos destacá-lo artificialmente do panorama global da PG à guisa de facilitação do argumento em nada se diferencia da semiologia psiquiátrica clássica, como era mesmo a pretensão do autor. A PG não almejava inovar em termos de psicopatologia, mas sim em termos de organização das psicopatologias. A única veleidade 


\section{O sentido da fenomenologia na Psicopatologia Geral de Karl Jaspers}

declarada de inovação de Jaspers foi, de certo modo, a fenomenologia, mas vista já com mais de um século de afastamento, também antes se insere na tradição do que com ela rompe. E mantém dela algo de extremo valor: a relevância da empatia como instrumento metodológico imprescindível para o acesso às vivências patológicas.

\section{A Fenomenologia e as totalidades}

O espírito da PG exige que agora investiguemos como se dá a progressão da fenomenologia-ciência parcial para outras totalidades. Aqui temos de retomar a noção das progressões acima apresentada. Excluindo-se a totalidadelimite da existência, existem totalidades de mesmo plano heurístico e totalidades de plano heurístico diverso. Examinemos em primeiro lugar a menos problemática e de melhor fortuna dessas relações dialéticas, a que se dá entre a fenomenologia e as ciências de investigação de relações de conexão do psiquismo, portanto, sua relação com uma totalidade de plano heurístico superior, ou seja, mais complexo.

O exame dessa relação mostra um papel relevante para a fenomenologia no plano acima. Embora esteja muito longe das pretensões desse artigo mostrar como se dão as relações entre método e resultados nos capítulos sobre relações de conexão entre conteúdos psíquicos, parece lícito afirmar que Jaspers situa em lugar primordial a distinção entre relações compreensíveis - de motivação - e causais - de explicação. Ora, o ponto crucial a determinar a linha de distinção entre aquilo que é compreensível ou não será exatamente a possibilidade de penetrar empaticamente nas vivências alheias para reconhecer como umas derivam das outras (ou não, no caso das causalidades). E esse papel é dado 


\section{Guilherme Messas}

fundamentalmente pela fenomenologia. Será ela portanto a avalista de última instância de todo o plano das relações de conexão, mostrando mais uma vez como Jaspers mantém a autonomia do plano menos complexo no mais. Muito embora a fenomenologia se mantenha presente também nos demais planos para se fazer um diagnóstico, por exemplo, é necessária a fenomenologia - é na dimensão das relações de conexão que seu papel tem a maior força dentro da PG, já que, para o diagnóstico, voltando ao mesmo exemplo, observações objetivas de rendimento também devem ser levadas em consideração. É importante ressaltar que a separação, permitida pela fenomenologia, entre fenômenos compreensíveis e explicáveis manteve seu valor também na corrente fenomenológica de psiquiatria e psicopatologia, constituindo talvez o único ponto de concordância - no mínimo, o único polo de discussões fecundas entre Jaspers e os psiquiatras fenomenólogos.

O mesmo não se pode dizer das relações da fenomenologia na PG com a sua totalidade de mesmo plano, ou seja, o estado momentâneo da consciência. Em tese, essa totalidade deveria estar no mesmo plano heurístico da fenomenologia. Como afirmamos, ela procura discriminar se as vivências fenomenologicamente determinadas ocorreram na plena clareza de consciência ou não. Esta somente autoriza ou anula os achados da fenomenologia. É uma relação surpreendentemente simples para um pensamento tão complexo como o de Jaspers. Há que se investigar o porquê dessa escassez de articulação, caracterizada por uma mera relação do tipo tudo-ou-nada, sem nuances. Para o entendimento dessa condição é necessário investigar em primeiro lugar o artigo de 1912, no qual Jaspers recusa para a fenomenologia uma importantíssima acepção de totalidade:

“Devemos começar com uma clara representação do que ocorre de fato com o paciente, do que realmente experimenta...; neste estágio, no presente 


\section{O sentido da fenomenologia na Psicopatologia Geral de Karl Jaspers}

estado da fenomenologia, parece haver um grupo numeroso de fenômenos entre os quais nenhuma relação pode ser percebida. Sensopercepção e ideias, alucinações e delírios parecem mais ser fenômenos separados por um abismo do que unidos por transições. Tais fenômenos, totalmente não relacionados, podem apenas ser situados sob diferentes rubricas e não podem ser organizados por nenhuma padrão particular dentro da vida psíquica" (op. cit. p. 1320).

Embora Jaspers reconheça a ocorrência de transições vivenciais, nega de princípio - e essa negação mantém-se intacta ao longo da PG - que os fenômenos claramente distintos entre si possam ser reduzidos a um termo comum que os articule. Ou seja, nega algum valor - no mínimo heurístico para a noção de estrutura no campo da fenomenologia. Essa recusa, que é veemente, surgindo em diversos pontos da PG, investe contra as possibilidades de investigação de uma estrutura unificadora que, estando presente nas diversas modalidades de experiência descritas pela fenomenologia (não estamos pensando aqui numa estrutura abstrata), revele suas conexões relativas recíprocas a partir do exame das suas condições de possibilidade. É inegável que uma noção de estrutura como condição de possibilidade unificadora da diversidade fenomenológica das vivências dos pacientes é exatamente uma totalidade semelhante às concebidas por Jaspers. Rejeitada para o campo das ciências empíricas a possibilidade de aplicação dessa totalidade de infinita riqueza e nuances para a fenomenologia, resta apenas a outra totalidade, do estado momentâneo. Esta, não deixando de ser uma condição de possibilidade, não é, no sentido forte do termo, uma totalidade de mesmo plano, já que não é unificante, ou seja, não permite um entendimento aprofundado da organização da fenomenologia, apenas a viabiliza. Estaria, a rigor, em um plano heurístico inferior à fenomenologia, o campo das ciências neurológicas (Nota: Jaspers inclui nesta seção lado a lado o nível de consciência "neurológico" e as 


\section{Guilherme Messas}

alterações psicótica da consciência, o que parece ser difícil de se justificar, levando a confusões, já que exigem abordagens metodológicas distintas).

A recusa da introdução das condições de possibilidade no campo das ciências empíricas sulca profundamente as fronteiras entre a psicopatologia fenomenológica e a obra de Jaspers. Assumindo o risco que as grandes simplificações exigem, podemos dizer que, embora haja grande diversidade de compreensões e desenvolvimentos da psicopatologia fenomenológica, tanto uma investigação histórica (Tatossian, 2006) quanto um exame das publicações específicas da área seja em português ( $\underline{\text { www.revistapfc.com.br }}$ ), italiano (http://www.rivistacomprendre.org/), inglês (http://www.brill.com/journalphenomenological-psychology) ou francês (Charbonneau, 2010), permitem a definição de fenomenologia como o estudo das condições de possibilidade das vivências. Declaradamente, Jaspers não entendia desse modo a fenomenologia.

Essa recusa merece ser investigada brevemente por duas frentes, já que não se deu de modo negativo, ou seja, como silêncio em relação ao tema. Em primeiro lugar, vale investigar o tratamento que Jaspers devotou à categoria psicopatológica mais frequentemente relacionada ao entendimento da fenomenologia como estudo das totalidades estruturantes das vivências: mundo.

Já o ponto da obra no qual o estudo do mundo se situa é elucidativo. Ele faz parte do capítulo "Fatos objetivos com significado", ladeando estudos como da fisiognomia, mímica ou escrita. O mundo para Jaspers é ou o "local” no qual se desenrola a vida humana, favorecendo-a ou restringindo-a, ou o universo interno do paciente lançado no exterior. É muito mais a expressão de uma experiência vivencial íntima do que um imbricamento profundo e inextricável entre o polo do sujeito e o polo da alteridade, embora Jaspers não recuse essa gênero de dualidade. É, de certo modo, uma concepção fraca de mundo, se 


\section{O sentido da fenomenologia na Psicopatologia Geral de Karl Jaspers}

comparada a certas psicopatologias fenomenológicas, nomeadamente a de Binswanger, para ficarmos nos clássicos, nas quais a estrutura das vivências já é preparada a priori pelo modo de assentamento primordial no mundo no qual as consciências estão imersas. Para Jaspers “...a vida é uma polêmica com o mundo..." (Jaspers, 1959b, p. 271), afirmação que traz em seu bojo a ideia de que eu e mundo estejam frente a frente, numa separação que impede a incorporação de uma noção de totalidade. Seja como for, o mundo para Jaspers está fora do campo de interesse da fenomenologia.

Mas Jaspers não deixou de examinar os primórdios da psicopatologia fenomenológica de língua alemã, estudando obras de autores centrais como Straus, von Gebsattel, Kunz e Binswanger (Nota: estes autores, embora alinhem-se à grande corrente fenomenológica, não se denominavam estritamente, sobretudo no início, fenomenólogos, utilizando outros termos relacionados à fenomenologia, como psicopatologia genético-construtiva (von Gebsattel) ou Daseinsanalyse (Binswanger), cujas especificidades não cumpre aqui examinar). Suas análises deixam-nos um legado de valor para a psicopatologia fenomenológica e ao mesmo tempo revelam mais uma vez um ponto de corte sobre o qual já falamos e com o qual queremos encerrar este artigo.

Jaspers experimenta respeito em relação ao fato da nascente psicopatologia fenomenológica não deslizar para as excessivas simplificações que tanto critica na psicanálise e nas "mitologias do cérebro". Reconhece que “São distintos os modernos esforços genético-contrutivos. Não projetam decididamente uma teoria total,... têm uma atitude não fanática, atuam por vezes como um dar sentido humano..." (Jaspers, 1959b, p. 458). Por outro lado, não deixa de neles lançar um reproche fundamental. Indaga-se a respeito de ser desconhecido para essa psicopatologia “Por que a mesma perturbação básica (a 


\section{Guilherme Messas}

estrutura que acima mencionamos) dar lugar ora a uma, ora a outra manifestação..." (Jaspers, 1959b, p. 454). Ou seja, os fenomenólogos iniciais, ao identificarem uma estrutura organizadora dos fenômenos - no caso, a paralisação da temporalidade - chegaram a um ponto comum excessivamente genérico, que servia igualmente à obsessão, transtorno bipolar e esquizofrênicos. Dar solução a essa pertinente crítica de Jaspers segue sendo um desafio para a psicopatologia fenomenológica, pois aceitar irrefletidamente que a paralisação da temporalidade justifique fenômenos de tanta diversidade incorre efetivamente em erro do tipo "abstração teórica", recusado também pela psicopatologia fenomenológica.

Contudo, diferentemente da psicopatologia fenomenológia, para quem esse eventual erro seria uma má conclusão tomada de uma investigação empírica legítima, para Jaspers, esse é um erro de princípio: “A teoria que está aqui em discussão dirige-se ao todo do ser humano. Isto, no entanto, é tema do filosofar, enquanto a ciência refere-se sempre a aspectos determinados do abarcante (Umgreifende)" (Jaspers, 1959b, p. 455). Se, de um lado, a psicopatologia fenomenológica desenvolve-se aprimorando cada vez mais no campo empírico a identificação das condições de possibilidade das vivências e suas relações de gênese, Jaspers, por outro, limita-se a excluir do empirismo científico esse estilo de busca pela totalidade. Alerta-nos para o embuste contido no gosto, que nos espreita a todos, por universalizações; porém, acaba por empobrecer o quadro da ciência à medida que reserva este vasto setor do saber exclusivamente para a indagação filosófica. $O$ ponto de transmissão conceitual dessa linha de corte da PG é a fraqueza com que a noção de mundo é entendida. O ponto filosófico dessa separação se dá por uma fusão entre o heurístico e o ontológico na fenomenologia. (Nota: Essa fusão - a nosso ver precipitada - talvez se justifique pelo abandono precoce da prática psiquiátrica por Jaspers. O próprio autor, na mencionada introdução à sétima edição, diz 


\section{O sentido da fenomenologia na Psicopatologia Geral de Karl Jaspers}

que uma atualização da obra contendo as produções das duas últimas décadas teria exigido uma imersão em alguma clínica psiquiátrica (p. V)). Jaspers, ao dizer, corretamente, que o ontológico só pode ser objeto da filosofia, exclui a possibilidade de que o plano heurístico possa se aventurar com lógica e precisão também no campo de totalização das experiências primárias de mundo. A corrente fenomenológica, que muito também se dedica às reflexões ontológicas, contudo, tem-se caracterizado por uma investigação metódica de totalidades vivenciadas que merece ser intitulada ciência empírica, sobretudo se acolher algumas das agudas críticas jasperianas.

\section{Conclusões}

A obra-prima de Jaspers, a Psicopatologia Geral, continua sendo justamente considerada um trabalho capital para a reflexão filosófica em psicopatologia e psiquiatria. Seu valor primordial e original reside na articulação estruturada dos métodos em psicopatologia a partir dos quais seus resultados devem ser ajuizados. Instituído por uma forte relação entre partes e todo, o espírito da obra exige que cada ciência parcial apenas possa ser examinada desde essa perspectiva. Nesse sentido, a fenomenologia em Jaspers tem, segundo o próprio autor, um valor subordinado, apenas como um dos métodos de investigação da mente humana adoecida.

Como método em particular, afasta-se da psicopatologia fenomenológica pela recusa de captação de uma totalidade individual empírica que organize a pluraliadade das modalidades fenomenológicas. Como filosofia da existência, aproxima-se fortemente da psicopatologia fenomenológica, à medida que seus temas e concepções de mundo são idênticos. Em especial, pela procura de uma 


\section{Guilherme Messas}

individualidade existencial que vai além das possibilidades de esgotamento pelas categorias científicas. Com essa posição, defende a cultura - medicina e psicopatologia incluídas - das amarras da tecnologização desumanizante (Jaspers, 1959b). Jaspers, na PG, nos deixa um grande legado para a filosofia da psiquiatria, enobrecido por reflexões existenciais; mas uma acanhada ciência fenomenológica.

\section{Referências Biliográficas}

Charbonneau G. (2010). Introduction à la psychopathologie phénoménologique. Tomos I e II. MJW Fédition.

Comprendre. Archive International pour l'Anthropologie et la Psychopathologie Phénoménologiques. Publicação eletrônica: http://www.rivistacomprendre.org/.

Jaspers K. (1959a). Allgemeine Psychopathologie. Sétima edição. Springer Verlag. As traduções são de responsabilidade do autor.

Jaspers K. (1959b). Der Artz im technischen Zeitalter. Universitas - Zeitschrift für Wissenschaft, Kunst und Literatur. v. 4, pp.337-354.

Jaspers K. (1968). The phenomenological approach in psychopathology. Brit J Psychiat. V.114, pp.1313-1323.

Journal of Phenomenological Psychology.(http://www.brill.com/journalphenomenological-psychology).

Psicopatologia Fenomenológica Contemporânea. Publicação eletrônica: (http://www.revistapfc.com.br/).Tatossian A. (2006). A fenomenologia das psicoses. Editora Escuta. 